\title{
Stress dose steroids: the dogma persists
}

\author{
Kristine Urmson, MD FRCPC (1)
}

Received: 16 August 2019/Revised: 28 August 2019/Accepted: 28 August 2019/Published online: 23 September 2019

(C) Canadian Anesthesiologists' Society 2019

\section{To the Editor,}

The use of stress dose steroids has become entrenched in perioperative management and medical teaching for more than six decades. Nevertheless, the recommendation for using "stress dose steroids" has rarely been challenged.

This dearth of evidence for its use has been highlighted over many decades in numerous review articles, which all lament the lack of robust data. A 2012 Cochrane review of the only two randomized studies comparing stress dose steroids and placebo with respect to secondary adrenal insufficiency succinctly concludes that "Based on current available evidence, we are unable to support or refute the use of supplemental perioperative steroids for patients with adrenal insufficiency during surgery." ${ }^{1}$ These studies, albeit small, suggest the possibility of fruitless treatment driven by dogma.

We attempted a multicentre randomized-controlled trial to compare physiologic steroids (intervention group) with stress dose steroids (control group) for minor surgical procedures in pediatric patients with primary adrenal insufficiency. Nevertheless, numerous other institutions declined to participate, stating they rarely use stress dose steroids. Instead, we surveyed pediatric anesthesiologists and pediatric endocrinologists in Canada regarding attitudes towards stress dose steroids for low stress surgeries, which showed a dramatic difference $(45 \%$ of anesthesiologists would give steroids compared with $92 \%$

K. Urmson, MD FRCPC ( $\square)$

Department of Anesthesiology, Perioperative Medicine and Pain Management, University of Saskatchewan, Saskatoon, SK,

Canada

e-mail: kristine.urmson@usask.ca of endocrinologists). In addition, consultation between pediatric anesthesiologists and pediatric endocrinologists was reported to be infrequent. ${ }^{2}$ This is consistent with a recent survey of Canadian anesthesiologists and general internists which also showed discrepancy in management of stress dose steroids and uncertainty regarding guidelines. $^{3}$

Recent evidence suggests healthy children having minimally or moderately invasive urologic procedures had no significant rise of cortisol perioperatively, though three patients had normal levels preoperatively and intraoperatively with a small rise postoperatively. ${ }^{4}$ This disputes classic pediatric endocrinology teaching that stress dose steroids are needed to mitigate the stress of general anesthesia.

Conversely, anesthesiologists may not appreciate the differences in adrenal insufficiency. Secondary adrenal insufficiency likely does not require stress dose steroids. Nevertheless, steroid management is critically important to children with primary adrenal insufficiency. A cohort study from the UK showed a three-fold increase in mortality in children with congenital adrenal hyperplasia compared with children without primary adrenal insufficiency. ${ }^{5}$

Perhaps the fundamental difference at the heart of the controversy regarding perioperative stress dose steroids is that anesthesiologists see increased cortisol as an adverse event to mitigate, while endocrinologists expect this as a natural phenomenon that we need to replicate in patients with adrenal insufficiency.

Despite the evolution of stress dose steroids over the last 60 years, we are making little progress in evidence-based medicine and optimizing the complex multidisciplinary care for pediatric patients with adrenal insufficiency. 
Conflicts of interest None declared.

Editorial responsibility This submission was handled by Dr. Hilary P. Grocott, Editor-in-Chief, Canadian Journal of Anesthesia.

Financial disclosures None.

\section{References}

1. Yong SL, Coulthard P, Wrzosek A. Supplemental perioperative steroids for surgical patients with adrenal insufficiency. Cochrane Database Syst Rev 2012; 12: CD005367. DOI: https://doi.org/10. 1002/14651858.cd005367.pub3.

2. Nour MA, Gill H, Mondal P, Inman M, Urmson K. Perioperative care of congenital adrenal hyperplasia - a disparity of physician practices in Canada. Int J Pediatr Endocrin 2018. DOI: https://doi. org/10.1186/s13633-018-0063-4.

3. Groleau C, Wong MJ, Hung O, Morin SN, Vautour L, Bessissow A. Perioperative glucocorticoid stress dosing: a survey of anesthesiologists and general internists. Can J Anesth 2018; 65: 1387-9.

4. Taylor LK, Auchus RJ, Baskin LS, Miller WL. Cortisol response to operative stress with anesthesia in healthy children. J Clin Endocrinol Metab 2013; 98: 3687-93.

5. Swerdlow AJ, Higgins $C D$, Brook $C D$, et al. Mortality in patients with congenital hyperplasia: a cohort study. J Pediatr 1998; 133: 516-20.

Publisher's Note Springer Nature remains neutral with regard to jurisdictional claims in published maps and institutional affiliations. 